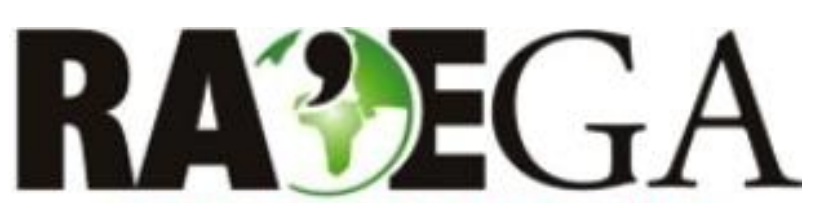

O ESPAÇO GEOGRÁFICO EM ANÁLISE

\title{
DESAFIOS E POTENCIALIDADES DAS PEQUENAS CIDADES PARA 0 DESENVOLVIMENTO NO CONTEXTO DE UMA SOCIEDADE URBANA: ALGUNS APONTAMENTOS COM BASE NA REALIDADE DE FRUTAL-MG E SÃO GOTARDO-MG
}

\section{CHALLENGES AND POTENTIAL OF SMALL CITIES FOR DEVELOPMENT IN THE CONTEXT OF AN URBAN SOCIETY: SOME NOTES BASED ON REALITY OF FRUTAL-MG AND SÃO GOTARDO-MG}

\author{
Lidiane Aparecida Alves \\ E-mail: lidianea@yahoo.com.br \\ Adriano Reis de Paula e Silva \\ E-mail: prof.eng_adrianoreis@yahoo.com.br
}

Recebido em: 03/10/2014

Aceito em: 05/02/2016

\section{Resumo}

A quantidade de pequenas cidades na rede urbana brasileira é significativa, sendo que os municípios com população de até 50 mil habitantes concentravam no ano de 2010 40\% da população do país. Destas cidades, destacamos aquelas localizadas nas áreas de expansão da agricultura moderna, que têm sua economia bastante vinculada às atividades deste complexo e amplo setor econômico, e têm incorporado novas dinâmicas econômicas e territoriais, para atender aos interesses de reprodução do capital, as quais são denominadas por Elias (2006) de "cidades do agronegócio". Em tais cidades, verifica-se uma simultaneidade de processos, como sua crescente importância, com relações estabelecidas com múltiplos territórios, graças à incorporação de elementos da globalização e das tecnologias de informação e comunicação (TIC's) no âmbito do processo produtivo, especialmente pelo consumo produtivo. O objetivo do artigo é apresentar algumas considerações sobre a situação das dimensões básicas à reprodução social e, que, portanto encontram-se entre as questões prioritárias para o desenvolvimento local. Logo, por apresentar algumas similaridades são considerados como exemplos as pequenas cidades de São Gotardo (31.819 habitantes) e Frutal (53.460 habitantes), localizadas no estado de Minas Gerais. Conclui-se que, ainda que existam entraves no planejamento, em ambas as cidades as condições socioeconômicas são relativamente boas, sem graves problemas sociais. Suas economias são baseadas na agricultura moderna, a qual condiciona a dinâmica e organização intraurbana, bem como as características demográficas, 
especialmente no que diz respeito à migração e a supremacia da população do sexo masculino que trabalha no campo. Notadamente em São Gotardo, a prática da agricultura moderna é mais intensa podendo ter reflexos na saúde da população local, o que desperta preocupação e demanda estudos específicos para melhor compreensão e tomada de medidas.

Palavras-Chave: Pequenas Cidades; Condições socioambientais; Perspectivas.

\begin{abstract}
The quantity of small cities in the Brazilian urban network is significant, once municipalities with a population near to 50 thousand inhabitants concentrated in $201040 \%$ of the country's population. About these cities, we call attention to those who are located in the expansion areas of modern agriculture, that their economy are very linked to the activities of this complex and large economic sector, and have incorporated new economic dynamics and territorial to correspond the capital production interests, which are called by Elias (2006) of "cities of agribusiness". In such cities, there is a simultaneity of process, as its increasing importance, with establish of relationships with multiple territories, and all about that thanks to the incorporation of elements of globalization, information and communication technologies (ICT) in this process, especially by the productive consumption. The goal of the present study is to present some considerations about the situation of basic dimensions of social reproduction and which therefore are among the priority issues for local development. Thus, by presenting some similarities, are considered as examples the small cities of São Gotardo (31,819 inhabitants) and Frutal (53 460 inhabitants), located in the state of Minas Gerais. We conclude that, although there are barriers in planning, in both cities, the socioeconomic conditions are relatively good, without serious social problems. Their economies are based on modern agriculture, which affects the dynamics and Intraurban organization, as well as demographic characteristics, especially about issues involving migration and the supremacy of the male working population in the field. Particularly in the Gotthard, the practice of modern agriculture is most intense, and it may be reflected in the local population's health, which is concern and demand specific studies for better understanding and taking action.
\end{abstract}

Keywords: Small Cities; Social and environmental conditions; Perspectives.

\title{
1. INTRODUÇÃO
}

Nos últimos dois séculos vivenciamos as explosões demográfica e urbana, sendo a primeira associada a fatores como: regulamentação das 
ALVES, L. A.; SILVA, A. R. P

DESAFIOS E POTENCIALIDADES DAS PEQUENAS CIDADES PARA O DESENVOLVIMENTO NO CONTEXTO DE UMA SOCIEDADE URBANA: ALGUNS APONTAMENTOS COM BASE NA REALIDADE DE FRUTAL-MG E SÃO GOTARDO-MG

relações de trabalho (com a consolidação de direitos), avanços na medicina e, consequentemente redução da mortalidade e aumento na longevidade etc. já a segunda guarda intrínsecas relações com: a migração campo-cidade, a industrialização, as transformações na estrutura e nas relações de trabalho e de propriedade no campo (concentração fundiária, inserção de novas estruturas produtivas alinhadas ao agronegócio), entre outros.

Tais processos resultaram na concentração de mais da metade da população mundial em cidades, tiveram inicio na Europa e América do Norte e têm destaque, no momento atual, nos países do hemisfério sul, principalmente África e América do Sul ${ }^{1}$, e na Ásia. Onde torna-se comum a formação das cidades com mais de 1 milhão de habitantes, das megacidades -com mais de 10 milhões de habitantes e, até mesmo, de metacidades- com de mais de 20 milhões de pessoas ${ }^{2}$, a ritmos mais intensos que outrora, em contextos em que não há o acompanhamento do provimento de recursos infraestruturais e o suprimento das demandas, o que, por vezes, implica em crises, que se manifestam sob diversas facetas, com complexidade e dimensões, relativamente, proporcionais à dimensão destas cidades. No Brasil, entre 1956 e 2010 as cidades milionárias, ou seja, as cidades que concentram mais de 1 milhão de habitantes, passaram de 2 para 15.

Gráfico 1: População mundial total por classe de tamanho da cidade (milhões)

\footnotetext{
${ }^{1}$ Contudo é importante destacar que em alguns países da América do Sul, como o Brasil devido a fatores como a própria urbanização, o planejamento familiar via utilização de métodos contraceptivos, a mudanças ideológicas etc. as taxas de crescimento vegetativo já não são tão elevadas, haja vista a redução do número de filhos por mulher, que passou de 6,3 em média nos anos de 1960 para cerca de 2,3 atualmente, estando praticamente na taxa de reposição populacional. Com isso a tendência é que em médio prazo o crescimento demográfico seja estabilizado, tal como ocorre nos "países desenvolvidos" que possuem baixas taxas de natalidade, fecundidade e mortalidade.

${ }^{2}$ Os termos megacidade e metacidades foram criados pela ONU (Organização das Nações Unidas), o primeiro em meados da década de 1990 e o segundo na década de 2010, quando especialistas daquela organização observaram que algumas cidades estavam aumentando seus contingentes populacionais de forma muito mais acentuada do que outras, em especial nos países subdesenvolvidos, especialmente na Ásia, que tem hoje sete das 10 cidades mais populosas do mundo. Dentre elas Delhi e Xangai na liga das metacidades. (UN-HABITAT 2012).
}

R. Ra'e Ga - Curitiba, v. 35, p.7 -37 , Dez/2015 
DESAFIOS E POTENCIALIDADES DAS PEQUENAS CIDADES PARA O DESENVOLVIMENTO NO CONTEXTO DE UMA SOCIEDADE URBANA: ALGUNS APONTAMENTOS COM BASE NA REALIDADE DE FRUTAL-MG E SÃO GOTARDO-MG

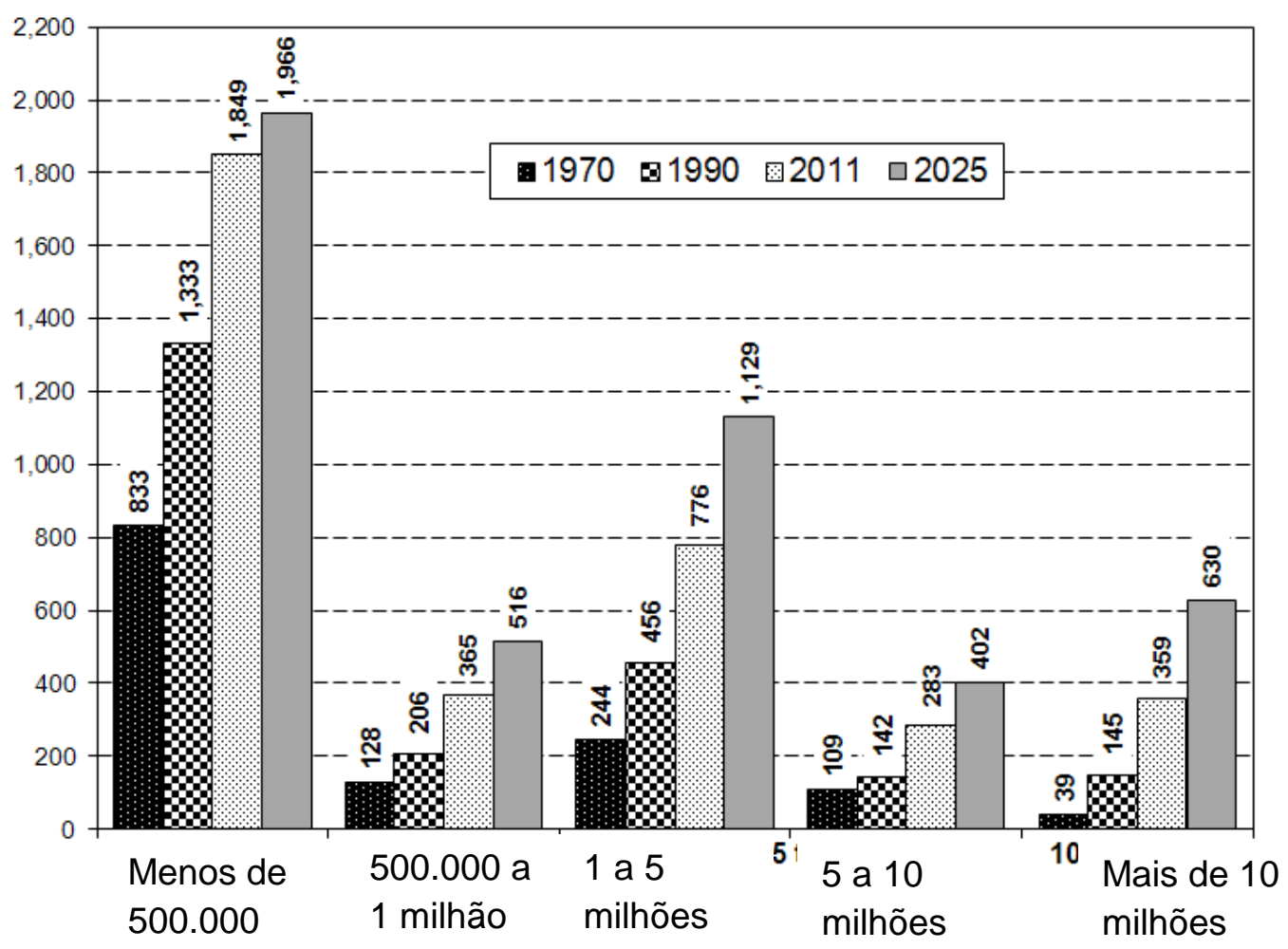

Fonte: Nações Unidas, Departamento de Assuntos Econômicos e Sociais, Divisão de População: Perspectivas de Urbanização Mundial, de 2011 Revision. New York, 2012.

Contudo, ainda que este não seja o foco de muitos estudos, também foi significativo o aumento do número de cidades pequenas, especialmente as com menos de 50 mil habitantes, gráfico 2. Cabe ressaltar que segundo a classificação do IBGE, são pequenas cidades aquelas com população inferior a 100 mil habitantes, no entanto, destaca-se que para além do critério populacional, historicamente associado a noção de urbanização, geograficamente para a definição da categoria de cidades é salutar considerar também critérios como seu papel, sua centralidade, na rede urbana, de acordo com o contexto regional, ou seja, considerar sua hinterlândia e as relações nela estabelecidas, ou de acordo com a abordagem do estudo outros critérios como: os diversos tipos de comunidades e considerando, por exemplo, as que possuem funções político-administrativas e comerciais, o tamanho em relação a outras comunidades, existência de uma divisão do trabalho que não incluía o trabalhador rural, ocorrência de edifícios monumentais, presença de uma classe de artesãos etc. (IBGE, 2015). 
ALVES, L. A.; SILVA, A. R. P

DESAFIOS E POTENCIALIDADES DAS PEQUENAS CIDADES PARA O DESENVOLVIMENTO NO CONTEXTO DE UMA SOCIEDADE URBANA: ALGUNS APONTAMENTOS COM BASE NA REALIDADE DE FRUTAL-MG E SÃO GOTARDO-MG

Além da possiblidade de utilização de vários critérios para delimitação e classificação, ainda não se tem um conceito de cidade pequena, mas apenas noções, ainda que este seja um termo recorrente em diferentes esferas da sociedade, conforme destaca Bacelar ( 2008, p.160) tais cidades, em geral, apresentam-se englobadas em um "limbo" conceitual e epistemológico, o que segundo o autor tornam penosas as análises geográficas acerca dessas localidades atualmente. Como principais referências para estudos, o autor cita:

[...] a classificação de Santos $(1979,1989,1996 b)$ e também as análises de Oliveira e Soares (2003) além dos estudos do IPEA (2000), especialmente as considerações de Camarano e Abramovay (1999), Abramovay (2000) e Veiga (2001), sobre a ruralização e as pequenas cidades, e ainda Bacelar (2003) sobre a pequena cidade, Corralo (2006) e sua interessante obra sobre a evolução do conceito e da proposta de municipalidade no mundo e no Brasil, Silva (2000) que realizou importante estudo sobre as pequenas cidades e suas relações internas, Ferreira, Aguilera e Carvalho (2000) sobre pequenas cidades, e mais Diniz, Poeta, Antonio e Silva (2000), que analisam os impactos $e$ as repercussões de modelos de desenvolvimento rural sobre algumas cidades, em especial aquelas em que o mundo rural é mais próximo das realidades das populações residentes. (BACELAR, 2008, p.160).

Cabe acrescentar que a própria noção de cidade varia entre os países: no Brasil a cidade é a sede do município, sendo a população desta e dos distritos contabilizada como urbana; há países em que é preciso que a aglomeração urbana possua mais de 20 mil habitantes para ser considerada cidade; em outros é preciso que exista infraestrutura urbana e algumas centenas de pessoas que se dediquem a atividades secundarias e terciarias para que haja uma cidade.

Embora tenham menor representatividade em termos populacionais, a categoria das pequenas cidades representa a maioria das cidades brasileiras e possuem grandes singularidades e complexidades. Destas cidades, destacamos aquelas localizadas nas áreas de expansão da agricultura moderna, que têm sua economia bastante vinculada às atividades deste complexo e amplo e setor econômico, e têm incorporado novas dinâmicas econômicas e territoriais, para atender aos interesses de reprodução do capital. Para Elias (2006, p. 294) as cidades, "cujas funções de atendimento às 
DESAFIOS E POTENCIALIDADES DAS PEQUENAS CIDADES PARA O DESENVOLVIMENTO NO CONTEXTO DE UMA SOCIEDADE URBANA: ALGUNS APONTAMENTOS COM BASE NA REALIDADE DE FRUTAL-MG E SÃO GOTARDO-MG

demandas da agricultura científica globalizada são hegemônicas sobre as demais funções", são definidas como "cidades do agronegócio".

Em tais cidades, verifica-se, então uma simultaneidade de processos, como sua crescente importância, com relações estabelecidas com múltiplos territórios, graças à incorporação de elementos da globalização e das tecnologias de informação e comunicação (TIC's) nas suas funções no âmbito do processo produtivo, neste caso destaca-se a ampliação do consumo produtivo, que conforme destacado por Santos (2009) adapta as cidades ao rural e contribui para aumentar a importância das mesmas do ponto de vista demográfico, econômico e da divisão do trabalho.

Contudo, por outro lado, por vezes, em tais cidades ocorre a convivência de situações desiguais, já que podem existir os problemas sociais e ambientais, como a falta de moradia, insuficiência de serviços básicos (saneamento ambiental, asfalto, iluminação, etc.), a sazonalidade do emprego e outros, pois como esclarece p. 166 "Os problemas urbanos das pequenas cidades são os mesmos vistos em cidades de porte médio e grande. A diferença reside na escala".

Gráfico 2: Percentual de municípios brasileiros por dimensão demográfica (19502010).

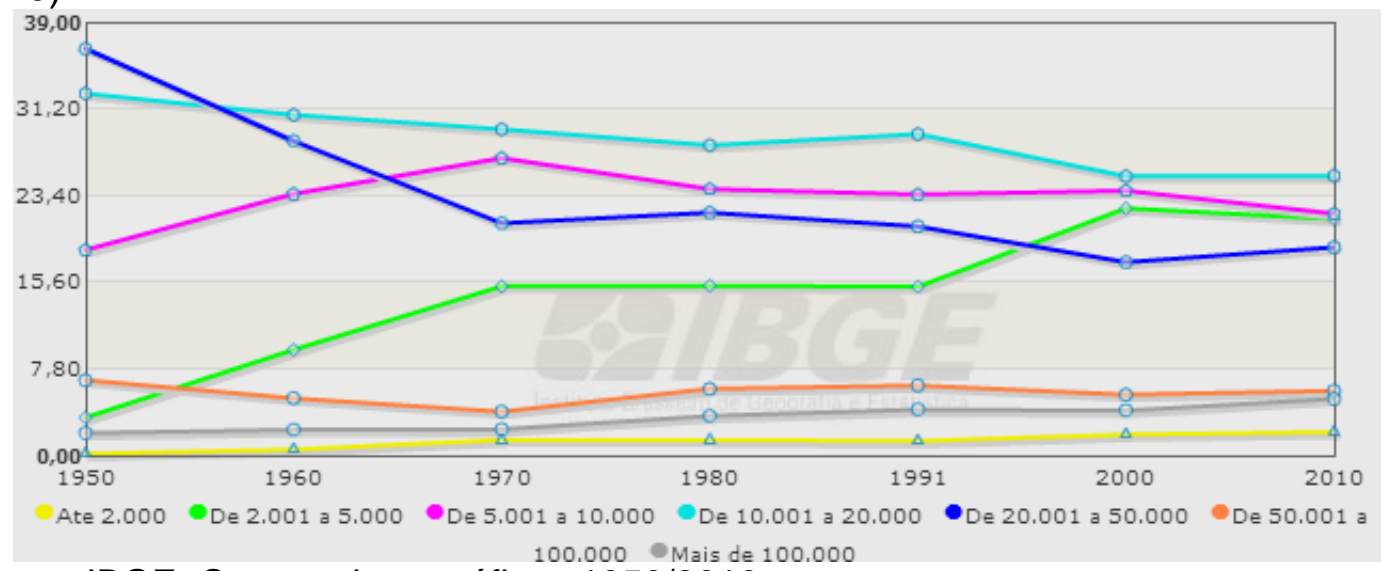

Fonte: IBGE, Censos demográficos 1950/2010.

Entre as décadas de 1950 e 2000 os municípios com menos de 20 mil habitantes passaram de 1.791 para 4.643 , um aumento de $61,4 \%$, cujo aumento dentre outros fatores deve-se aos desmembrados e emancipados. Entre 2000 e 
DESAFIOS E POTENCIALIDADES DAS PEQUENAS CIDADES PARA O DESENVOLVIMENTO NO CONTEXTO DE UMA SOCIEDADE URBANA: ALGUNS APONTAMENTOS COM BASE NA REALIDADE DE FRUTAL-MG E SÃO GOTARDO-MG

2010, destaca-se que muitas destas cidades tiveram um crescimento demográfico, que assegurou que passassem a categoria de 20 a 50 mil habitantes, que passou de 64 em 1950 para 583 municípios em 2010. Assim, os municípios com menos de 50 mil habitantes são maioria, estes representavam em 2010 mais de 90\%. Afinal, conforme apontam vários estudos, ainda que, não represente uma mudança drástica no padrão de urbanização, a partir década de 1980 o ritmo de crescimento das grandes metrópoles vem reduzindo em relação ao aumento do crescimento das cidades de porte médio ${ }^{3}$, e até mesmo de algumas pequenas cidades, o que pode ser visto de forma positiva, pois assim ocorre uma distribuição mais equilibrada das atividades econômicas sobre o espaço. Sendo que tal fato pode representar tanto uma potencialidade como um desafio para o desenvolvimento destas cidades, dependendo das prioridades estabelecidas para a cidade especialmente pelos agentes políticos.

A escala local das pequenas cidades pode apresentar potencialidades para implementação de ações de planejamento, especialmente considerando que estas possuem perímetro urbano menos extenso e menor dimensão populacional, o que poderia facilitar a construção de espaços capazes de assegurar melhores condições de vida, especialmente em condições em que existam recursos financeiros e um quadro de funcionários experientes e eficientes. Assim, com a representatividade desta categoria de cidades na rede urbana brasileira, de modo geral, estas poderiam ser consideradas a estirpe para as cidades de categorias hierárquicas superiores sem problemas socioeconômicos e ambientais hoje latentes em várias cidades.

Por serem processos intrinsicamente relacionados, a relevância destas reflexões sobre a dinâmica das cidades torna-se ainda maior ao considerar as mudanças que ocorrem na estrutura demográfica, decorrentes de processos como a migração e o envelhecimento populacional que enquanto um subproduto da transição demográfica, decorrente, sobretudo do declínio da fecundidade e da

\footnotetext{
${ }^{3}$ Mais informações sobre as cidades médias podem ser obtidas em: AMORIM FILHO, O. B.. Cidades médias e organização do espaço no Brasil. Revista Geografia e Ensino, Belo Horizonte, v. 2, n. 5, p. 5-34. 1984. ANDRADE, T. A.; SERRA, R. V. (Org.). Cidades médias brasileiras. Rio de Janeiro: IPEA, 2001. BELLET, C. LLOP, J. M. Ciudades intermedias. Perfiles y pautas. Lleida: Milenio, 2003.
} 
DESAFIOS E POTENCIALIDADES DAS PEQUENAS CIDADES PARA O DESENVOLVIMENTO NO CONTEXTO DE UMA SOCIEDADE URBANA: ALGUNS APONTAMENTOS COM BASE NA REALIDADE DE FRUTAL-MG E SÃO GOTARDO-MG

mortalidade, consiste em um processo que, apresenta-se segundo as Nações Unidas de modo: inédito, generalizado, duradouro e com profundas implicações em várias facetas da vida.

Destaca-se ainda que, no caso das pequenas cidades, é necessário considerar as relações que estas mantêm com o campo, e têm reflexos importantes na conjuntura e processos verificados na estrutura e na dinâmica urbana e, igualmente no âmbito das questões demográficas. Logo, com o intuito de despertar a atenção para questões a serem pensadas, com vistas a assegurar 0 desenvolvimento em que estejam harmoniosamente presentes boas condições sociais, ambientais e econômicas, são feitos alguns apontamentos com base no contexto das pequenas cidades mineiras de São Gotardo (31.819 habitantes) e Frutal (53.460 habitantes), ambas localizadas na mesorregião Triângulo Mineiro/Alto Paranaíba e com a economia baseada na agricultura moderna, a qual condiciona a dinâmica e organização intraurbana, a partir das atividades de comércio e serviços que servem às atividades do campo, bem como as características demográficas, especialmente no que diz respeito à migração e à supremacia da população do sexo masculino que trabalha no campo.

É importante destacar que apesar da existência de similaridades, como a base econômica e a presença de migrantes, os municípios apresentam diferenças como aquelas relacionadas às características físicas do território, por exemplo, enquanto a Frutal tem uma área de 2.426,965 km² e localiza-se na divisa com o Estado de São Paulo, São Gotardo tem $866,087 \mathrm{~km}^{2}$, e localiza-se mais ao interior do Estado de Minas Gerais; e também relacionadas às relações de poder estabelecidas pelas elites locais nestes territórios, no sentido dos valores a serem difundidos e valorizados, dos investimentos prioritários, da divulgação da localidade e sua economia em diferentes escalas, etc. Fatores estes que, em certa medida, podem ser explicativos para a conjuntura atual e para as perspectivas de futuro desenhadas.

O objetivo foi tecer algumas considerações sobre a situação das dimensões básicas à reprodução social, que, portanto, encontram-se entre as questões prioritárias para o desenvolvimento local dos referidos municípios.

R. Ra'e Ga - Curitiba, v. 35, p.7 -37 , Dez/2015 
DESAFIOS E POTENCIALIDADES DAS PEQUENAS CIDADES PARA O DESENVOLVIMENTO NO CONTEXTO DE UMA SOCIEDADE URBANA: ALGUNS APONTAMENTOS COM BASE NA REALIDADE DE FRUTAL-MG E SÃO GOTARDO-MG

\section{MATERIAIS E MÉTODOS}

Para este artigo utilizou-se da revisão de bibliografia, de artigos, teses e livros que abordam direta e indiretamente questões relacionadas à temática a partir de diferentes pontos de vista. E também para a dimensão quantitativa realizou-se o levantamento de informações em diferentes fontes, como: Instituto Brasileiro de Geografia e Estatística (IBGE), Ministério da Saúde (MS) e Programa das Nações Unidas para o Desenvolvimento (PNUD) por meio do Atlas do desenvolvimento humano do Brasil.

\section{RESULTADOS E DISCUSSÕES}

\section{Mudança no "pensar" as cidades: a potencialidade das pequenas cidades}

As cidades pequenas são predominantes e têm papel relevante no conjunto de cidades que formam a rede urbana brasileira. Além disso,

[...] as cidades pequenas apresentam tanto interesse quanto as colméias urbanas modernas e é quase sempre mais difícil precisar seu mecanismo e o ritmo calmo de sua vida, do que analisar as rodas bem lubrificadas correndo a toda velocidade em metrópoles imponentes. (MONBEIG, 2004, p.280).

Contudo, os estudos sobre as pequenas cidades ainda apresentam-se envoltos de fragilidades, especialmente em relação a um arcabouço teórico que dê conta da heterogeneidade regional desta categoria de cidades. Além disso, ainda não se tem um conceito de cidade pequena, mas apenas noções, ainda que este seja um termo recorrente em diferentes esferas da sociedade.

Considerando a existência de diversas tipologias de pequenas cidades no limiar do século XXI, Corrêa (2007) aponta cinco padrões funcionais característicos, a saber: I) prósperos locais centrais ligados às áreas submetidas à intensa industrialização do campo, como ocorre no centro-sul brasileiro; II) pequenos centros funcionalmente especializados relacionados, sobretudo, à produção industrial de uma determinada mercadoria como Telêmaco Borba (destaque para o segmento de papel e celulose), no Paraná e 
Ibitinga (confecções), no Estado de São Paulo; III) cidades pequenas que foram transformadas em subúrbio-dormitórios como acontece em núcleos que estão em contiguidade a centros economicamente expressivos, como Londrina, no Paraná; IV) focos de concentração de trabalhadores agrícolas derivados do processo de modernização do campo, do aumento da concentração fundiária, etc.; V) núcleos dependentes de recursos externos que são típicos de áreas agrícolas muito pobres e esvaziadas demograficamente, sobrevivendo pelo envio de recursos externos, oriundos principalmente do governo federal e estadual.

No entanto, segundo Jurado da Silva (2011) em função dentre outros fatores dos impactos da globalização na sociedade e, por conseguinte, nos espaços e em suas relações, os estudos acerca das pequenas cidades tem ganhado corpo nos últimos anos, do mesmo modo que esta categoria de cidades, que têm "significados cada vez mais econômicos e ligados ao capital internacional, numa síntese de contatos e interações espaciais múltiplas e complexas".

Conforme a tabela 1, observa-se a importância das pequenas cidades como local de residência de muitos brasileiros. Cerca de $50 \%$ da população é residente em municípios com menos de 100 mil habitantes, sendo que em Minas Gerais esse percentual é ainda maior, $60 \%$ da população residente nas cidades pequenas. Tal fato, pode ser a evidencia de uma tendência do processo de urbanização para o século $X X I$, qual seja, a tendência de "interiorização das aglomerações urbanas". Nesta perspectiva, conforme vários estudiosos como Baeninger (1998) destacam que essas mudanças relacionadas com a reestruturação produtiva, levam à consolidação e 0 desenvolvimento de novo polos intra e interregionais. 
DESAFIOS E POTENCIALIDADES DAS PEQUENAS CIDADES PARA O DESENVOLVIMENTO NO CONTEXTO DE UMA SOCIEDADE URBANA: ALGUNS APONTAMENTOS COM BASE NA REALIDADE DE FRUTAL-MG E SÃO GOTARDO-MG

Tabela 1 - Brasil e Minas Gerais: indicadores sociais municipais da população dos municípios por classes $(2000,2010)$. $^{*}$

\begin{tabular}{|c|c|c|c|c|c|c|c|c|}
\hline \multirow{5}{*}{$\begin{array}{l}\text { POPULAÇÃO DOS } \\
\text { MUNICÍPIOS POR } \\
\text { CLASSES }\end{array}$} & \multicolumn{8}{|c|}{ POPULAÇÃO } \\
\hline & \multirow{3}{*}{\multicolumn{2}{|c|}{$\begin{array}{c}\text { TOTAL } \\
\text { HABITANTES }\end{array}$}} & \multirow{3}{*}{\multicolumn{2}{|c|}{$\begin{array}{c}\text { TOTAL } \\
\text { PERCENTUAL }\end{array}$}} & \multicolumn{4}{|c|}{$\begin{array}{c}\text { DISTRIBUIÇÃO } \\
\text { PERCENTUA (\%) }\end{array}$} \\
\hline & & & & & \multicolumn{4}{|c|}{ SITUAÇÃO DO DOMICÍLIO } \\
\hline & & & & & \multicolumn{2}{|c|}{ URBANA } & \multicolumn{2}{|c|}{ RURAL } \\
\hline & 2000 & 2010 & 2000 & 2010 & 2000 & 2010 & 2000 & 2010 \\
\hline Brasil & 169.872 .856 & 190.755 .799 & $100 \%$ & $100 \%$ & 81,2 & 84,4 & 18,8 & 15,6 \\
\hline Até 5.000 & 4.606 .246 & 4374345 & $3 \%$ & $2 \%$ & 50,1 & 56,3 & 49,9 & 43,7 \\
\hline De 5.001 até 10.000 & 9.370 .299 & 8541935 & $6 \%$ & $4 \%$ & 54,2 & 60,0 & 45,8 & 40,0 \\
\hline De 10.001 até 20.000 & 19.624 .321 & 19743967 & $12 \%$ & $10 \%$ & 56,4 & 60,9 & 43,6 & 39,2 \\
\hline De 20.001 até 50.000 & 28.864 .840 & 31344671 & $17 \%$ & $16 \%$ & 66,3 & 70,3 & 33,7 & 29,7 \\
\hline De 50.001 até 100.000 & 20.842 .828 & 22314204 & $12 \%$ & $12 \%$ & 81,2 & 81,0 & 18,8 & 19,0 \\
\hline De 100.001 até 500.000 & 39.755 .647 & 48565171 & $23 \%$ & $25 \%$ & 94,5 & 94,5 & 5,5 & 5,5 \\
\hline Mais de 500.000 & 46.808 .675 & 55871506 & $28 \%$ & $29 \%$ & 98 & 99,1 & 2,0 & 0,9 \\
\hline Minas Gerais & 17.905 .133 & 19.597.330 & $100 \%$ & $100 \%$ & 81,9 & - & 18,1 & - \\
\hline Até 5.000 & 868.725 & 855.217 & $5 \%$ & $4 \%$ & 54,4 & - & 45,6 & - \\
\hline De 5.001 até 10.000 & 1.866 .477 & 1.744 .504 & $10 \%$ & $9 \%$ & 57,1 & - & 42,9 & - \\
\hline De 10.001 até 20.000 & 2.434 .757 & 2.545 .609 & $14 \%$ & $13 \%$ & 64,5 & - & 35,5 & - \\
\hline De 20.001 até 50.000 & 3.075 .372 & 3.300 .894 & $17 \%$ & $17 \%$ & 76,1 & - & 23,9 & - \\
\hline De 50.001 até 100.000 & 2.626 .649 & 2.642 .693 & $15 \%$ & $13 \%$ & 89,2 & - & 10,8 & - \\
\hline De 100.001 até 500.000 & 3.755 .205 & 4.409 .560 & $21 \%$ & $23 \%$ & 96,1 & - & 3,9 & - \\
\hline Mais de 500.000 & 3.277 .948 & 4.098 .853 & $18 \%$ & $21 \%$ & 99,5 & - & 0,5 & - \\
\hline
\end{tabular}

* Nota da tabela: Resultados da amostra. - Ausência de dados disponíveis.

Fonte: IBGE - Censo Demográfico (SIDRA - Sistema IBGE de Recuperação Automática), 2012. Org.: REIS DE PAULA, 2012.

Se antes, as cidades pequenas podiam ser caracterizadas por uma economia baseada nas atividades agrícolas e por relações e influências restritas ao seu entorno, geralmente o campo (SANTOS, 1979), em decorrência dos avanços técnico-científico-informacionais, difundidos pela globalização, ocorrem várias transformações na organização espacial no contexto destas cidades. A modernização das atividades agrícolas, por 
ALVES, L. A.; SILVA, A. R. P

DESAFIOS E POTENCIALIDADES DAS PEQUENAS CIDADES PARA O DESENVOLVIMENTO NO CONTEXTO DE UMA SOCIEDADE URBANA: ALGUNS APONTAMENTOS COM BASE NA REALIDADE DE FRUTAL-MG E SÃO GOTARDO-MG

exemplo, segundo Oliveira e Soares (2003, p.9) implicou em reestruturações urbanas, pois com a "interdependência funcional entre campo e cidade essas últimas vão equipar-se, a fim de abastecer o campo". Assim, concordando com Santos (2009), as pequenas cidades:

[...] Antes, eram as cidades dos notáveis, hoje se transformam em cidades econômicas. As cidades dos notáveis, onde as personalidades notáveis eram o padre, o tabelião, a professora primária, o juiz, o promotor, a telegrafista, cede lugar à cidade econômica, onde são imprescindíveis o agrônomo (o que antes viviam nas capitais), o veterinário, o bancário, o piloto agrícola, o especialista em adubos, 0 responsável pelos comércios especializados. (SANTOS, 2009, p. 56).

É crucial pensar as pequenas cidades na perspectiva de cidades para 0 futuro e suas possibilidades para tal, para evitar que estas sejam, de certa forma, espaços para a concretização de processos, tal como aquele observado por Santos (2008) ao analisar o processo de urbanização nos países subdesenvolvidos, onde ocorreu, simultaneamente: "o crescimento demográfico e econômico, o progresso da informação e as tentativas da organização do espaço". Com isso, segundo Maricato (2000), apesar das transformações, especialmente pela materialização de uma sociedade urbana, em função das características da formação da sociedade brasileira, o crescimento urbano sempre se deu com exclusão social, parafraseando-a este "recria o atraso a partir de novas formas, como contraponto à dinâmica de modernização". Maricato (2000) concorda com a perspectiva de outros autores brasileiros como: Celso Furtado, Francisco de Oliveira, Florestan Fernandes, José de Souza Martins e Vanderley Guilherme, que estudaram o "desenvolvimento" do país, e relaciona a forma como este aconteceu tradicionalmente marcado pela desigualdade, com a presença de novos e antigos males na sociedade, especialmente nas cidades brasileiras, onde são anunciadas várias "tragédias urbanas". Perspectiva compartilhada também por Ferreira (2000).

Com foco no âmbito intraurbano, os processos devem ser divergentes daquele modelo de "desenvolvimento" que, concordando com Souza (2005), em muitos casos seria mais adequado se chamado de crescimento, R. Ra'e Ga - Curitiba, v. 35, p.7 -37 , Dez/2015 
DESAFIOS E POTENCIALIDADES DAS PEQUENAS CIDADES PARA O DESENVOLVIMENTO NO CONTEXTO DE UMA SOCIEDADE URBANA: ALGUNS APONTAMENTOS COM BASE NA REALIDADE DE FRUTAL-MG E SÃO GOTARDO-MG

complexificação e até mesmo modernização das cidades, pois o desenvolvimento autêntico não se confunde com desenvolvimento econômico, mas combina também sistema político, valores e padrões culturais e a organização espacial. Na ausência de um desenvolvimento autêntico, por vezes, a cidade deixa de exercer a sua função social.

A realidade é desafiadora, já que coexistem de um lado os entraves criados pela recente e intensa urbanização, o desenvolvimento econômico e a modernização e de outro lado as fragilidades dos sistemas de gestão locais. Há, portanto um embate entre a "demanda e a oferta" de eficazes planejamento e gestão urbano/territorial, para que, a partir da escolha entre alternativas ocorra a condução da situação para a obtenção de uma realidade diferente da que até então tem se instalado em muitas cidades brasileiras, especialmente nas grandes. Neste sentido, tem se tornado comum a noção de que é requerido um conjunto de políticas públicas, especialmente aquelas de caráter preventivo; ações de planejamento que antecipem as demandas, valorizem as potencialidades e amenizem as fragilidades; além da articulação do planejamento com um eficiente processo de gestão, a fim de se evitar problemas comuns como a não aplicação dos planos elaborados, bem como a não continuidade, sem motivos justificáveis, de ações já iniciadas, etc. Mas, a prática, muitas vezes ocorre para cumprir requisitos burocráticos e evitar penalizações. Há vários entraves para o sucesso do processo de planejamento no âmbito das pequenas cidades. Dentre eles pode-se citar: a implementação de ações que contribuem para a perpetuação das desigualdades, criando desequilíbrios e vulnerabilidades socioambientais; a substituição do planejamento pela gestão torna-se comuns as ações apenas para "apagar os incêndios"; a ausência de pessoas qualificadas, tanto para a elaboração quanto para a implementação dos planos; entre outros. Como consequência, a impressão que se tem é que o processo de planejamento é ausente, ou que sua presença não altera os processos e a dinâmica da cidade.

Quando o foco se volta para o nível interurbano, a relação entre o tamanho da cidade e a possibilidade de efetividade das ações de planejamento, destaca-se que, em certos casos, algumas ações, como aquelas R. Ra'e Ga - Curitiba, v. 35, p.7 -37 , Dez/2015 
DESAFIOS E POTENCIALIDADES DAS PEQUENAS CIDADES PARA O DESENVOLVIMENTO NO CONTEXTO DE UMA SOCIEDADE URBANA: ALGUNS APONTAMENTOS COM BASE NA REALIDADE DE FRUTAL-MG E SÃO GOTARDO-MG

relacionadas ao provimento de infraestrutura urbana, poderiam ter resultados mais efetivos nas pequenas cidades, já que em função do perímetro urbano ser reduzido, os benefícios seriam para quase, ou mesmo, para a totalidade dos habitantes. De modo que estas cidades não chegariam a apresentar, e caso apresentassem seria de forma incipiente, certos problemas como: os relacionados aos resíduos, ao fornecimento de água, à coleta do esgoto, à circulação e acessibilidade, à habitação, ao lazer, etc., quando atingissem a dimensão demográfica de cidade média ou grande.

No Brasil, como em poucas outras realidades do mundo, a escala local, do município, tem sido beneficiada com a descentralização politicoadministrativa iniciada nas últimas décadas do século $X X$, com os artigos $182 \mathrm{e}$ 183 da Constituição Federal de 1988. A partir de então a política urbana adquire um novo viés, com a retomada com maior autonomia dos processos de planejamento e gestão urbana. Salutarmente, os avanços em termos legais têm permanecido, a aprovação em nível federal no ano de 2001, da Lei n.o 10.257, de 10 de julho de 2001, conhecida como Estatuto da Cidade; a implementação no ano de 2003 do Ministério das Cidades e suas secretarias de Habitação, Saneamento, Transporte e Mobilidade e Programas Urbanos e a regulamentação pelo Decreto federal 5.790 , de 25 de maio de 2006 do ConCidades, instância de gestão democrática da política urbana, entre outras iniciativas setoriais como nas áreas de habitação com a instauração do Sistema Nacional de Habitação de Interesse Social (SNHIS) em 2005, além da ressignificação dos Planos Diretores e, por conseguinte, dos planos setoriais, que assumem maior capacidade de autonomia e abertura para tratar de questões diversas, no nível local servem como exemplo. Isto, certamente, apresenta um grande avanço já que os problemas de cada lugar são singulares e, portanto têm soluções específicas.

Ainda na perspectiva de promover a (re)construção das cidades de forma que estas garantam melhores e crescentes qualidade de vida e bem-estar a toda a população, pelo acesso aos bens públicos essenciais como educação, moradia, transporte, emprego, etc., nos quais estão intrínsecos os fatores que determinam a saúde, e também as dimensões ambientais, politicas e R. Ra'e Ga - Curitiba, v. 35, p.7 -37 , Dez/2015 
econômicas; destaca-se a emergência de projetos cujo objetivo é despertar a atenção para a construção de cidades mais sustentáveis, saudáveis e democráticas. Neste sentido, de incentivar as cidades às mudanças, além dos avanços em termos legais viabilizados pelo Estado, têm surgido várias propostas. Como exemplo de iniciativa, que busca o engajamento dos municípios em escala nacional, a partir da assinatura da carta-compromisso, tem-se o Programa Cidades Sustentáveis, que incorpora a partir de 12 eixos temáticos as dimensões social, ambiental, econômica, política e cultural e as diferentes áreas da gestão pública. Onde, "cada um deles estão associados indicadores, casos exemplares e referências nacionais e internacionais de excelência" de modo a possibilitar que os municípios adeptos ao programa realizem o monitoramento dos resultados.

Tais ações devem ser incorporadas pelo processo de planejamento, reconhecido por órgãos como a OMS - Organização Mundial de Saúde - como capaz de promover comportamentos saudáveis ao investir nos diferentes ambientes: físico, social, econômico, cultural, por meio, por exemplo, do transporte público não motorizado, da prática de atividade física, da segurança alimentar, do saneamento básico, entre outros, cujas ações se desdobram em dimensões imateriais e em equidade, como índices de poluição atmosférica, de qualidade da água, de capital social, das oportunidades (de bens e serviços) locais solidariedade, participação, justiça, etc. Afinal, conforme destacam Melo; Soares (2011) os problemas socioambientais que afetam as cidades, em sua maioria estão ligados ao modelo de desenvolvimento da atual sociedade, de modo que

[...] soluções concretas para a construção de uma "nova" e melhor condição ambiental passam por um repensar da própria base econômica e política da sociedade. Por outro lado, medidas importantes devem ser tomadas de imediato pelo poder público e pela sociedade tais como: a aplicação das leis que regulam o uso do solo urbano e dos recursos naturais; lutas e ações pela democratização da moradia de qualidade (sócio-ambiental); formações de movimentos educativos em prol de uma cidade com qualidade ambiental e uma prática efetiva e consciente do planejamento urbano (MELO; SOARES, 2011, p.139). 
DESAFIOS E POTENCIALIDADES DAS PEQUENAS CIDADES PARA O DESENVOLVIMENTO NO CONTEXTO DE UMA SOCIEDADE URBANA: ALGUNS APONTAMENTOS COM BASE NA REALIDADE DE FRUTAL-MG E SÃO GOTARDO-MG

Eis, pois, que segundo Guerreiro (2006, p. 96) o planejamento e a gestão urbana devem ser estratégicos, antecipando às demandas, de modo a propiciar medidas de inclusão, sociais e espaciais e produzir novas oportunidades. Com base em Fischer (2002) o autor ainda destaca que tais processos podem vir a ser transformadores da mediação que: i) articula múltiplas escalas de poder; ii) coordena interorganizações eficazes; iii) promove aprendizagens coletivas; iv) comunica e difunde resultados; v) reavalia e recria estratégias, etc. Sendo que as tecnologias podem tornar-se importantes ferramentas auxiliares, afinal estamos na "era da informação" e da "sociedade em rede" conforme afirma Castells (1999) a utilização de tecnologias pode viabilizar 0 acompanhamento das transformações socioespaciais, sendo que a existência e manutenção de base de dados, combinada com meios de comunicação, pode ser o encaminhamento para tal.

Nesta perspectiva, da transformação da realidade a partir da escala local e das ações estratégicas para tal, destaca-se a importância da existência de conhecimentos e participação por parte de todos. Segundo Dowbor (2013) o município é a base para a construção do país, o que requer uma boa administração conciliada com a participação das pessoas. Contudo, para que haja participação é preciso que as pessoas tenham conhecimento das condições do local, para dizerem o que querem. Neste sentido, o estudioso destaca a relevância das mídias científicas para informar, por exemplo, as condições sociais do bairro, cujo conhecimento, apropriado pelos moradores pode transformar em pressão política e transformação.

\section{O contexto das cidades mineiras de Frutal e São Gotardo}

Por suas características, a constituição espacial das pequenas cidades em questão se insere, segundo a classificação de Corrêa (2000) na formação fundada na grande propriedade rural, a qual implica em uma rede urbana com a menor densidade e o maior espaçamento dos centros urbanos, em comparação com os outros dois casos, que são: a formação fundada na 
ALVES, L. A.; SILVA, A. R. P

DESAFIOS E POTENCIALIDADES DAS PEQUENAS CIDADES PARA O DESENVOLVIMENTO NO CONTEXTO DE UMA SOCIEDADE URBANA: ALGUNS APONTAMENTOS COM BASE NA REALIDADE DE FRUTAL-MG E SÃO GOTARDO-MG

pequena propriedade rural dos imigrantes europeus, que apresenta, inclusive uma hierarquia de centros mais clara, e a formação espacial de fronteira. Os municípios também, se inserem no contexto da modernização da agricultura via políticas e programas públicos implantados pelo governo federal na década de 1970, com o intuito de promover a ocupação das áreas de Cerrado, como o Programa de Desenvolvimento dos Cerrados (POLOCENTRO) e o Programa de Cooperação Nipo-Brasileiro para o Desenvolvimento dos Cerrados (PRODECER). Neste contexto, destaca-se que o município de São Gotardo foi beneficiado também pelo Programa de Assentamento Dirigido do Alto Paranaíba (PADAP) ${ }^{4}$, a partir do qual foi constituída a estrutura produtiva de commodities na região. A partir deste momento, foram intensas as modificações, e significativos os graus de aumento de urbanização (quantitativa e qualitativa ${ }^{5}$ ) e de desenvolvimento econômico de muitas cidades da região.

Ao analisar o processo de urbanização, sobretudo nestas regiões, cuja base econômica é a agricultura moderna, é preciso ter em conta algumas particularidades, relacionadas à ocupação, pois, mesmo com a residência na cidade, sendo contabilizada como urbana, parte da população continua a trabalhar no campo, a denominada por Santos (2009) de "população agrícola". Essa população é composta tanto pelos chamados boias-frias como pelos profissionais que desempenham atividades específicas, como os agrônomos, veterinários, técnicos em diferentes áreas, como montagem e manutenção de equipamentos agrícolas, gerenciamento e administração da propriedade e do processo de produção, etc. Segundo Santos (2009, p.63), tratando da

\footnotetext{
${ }^{4}$ Esse programa abrange área contigua de cerca de 60.000 ha pertencente aos municípios de Campos Altos, Ibiá, São Gotardo e Rio Paranaíba, onde havia um grande latifúndio de aproximadamente 20.000 ha. A Cooperativa Agrícola de Cotia (CAC) criada em 1927, já extinta, teve um papel fundamental no processo de distribuição dos lotes aos migrantes, principalmente de nacionalidade ou descendência japonesa, selecionados a ocupar e desenvolver a agricultura na região. Posteriormente em 1994, criou-se a Cooperativa Agropecuária Mista do Programa de Assentamento Dirigido do Alto Paranaíba Ltda (COOPADAP), incumbida do recebimento, beneficiamento, armazenagem e comercialização de cereais, grãos e hortifrutigranjeiros, bem como a revenda de insumos agrícolas.

${ }^{5}$ A urbanização, em termos quantitativos, trata-se do aumento numérico, absoluto e relativo, da população urbana, que tende a concentrar-se nas cidades. Enquanto, qualitativamente, trata-se da difusão do modo de vida urbano, com mudanças nos padrões de comportamento, implicando, entre outros, em mudanças no modo de consumo através da popularização do consumo de bens e produtos industrializados. (CORRÊA, 2001, p. 426).
}

R. Ra'e Ga - Curitiba, v. 35, p.7 -37 , Dez/2015 
DESAFIOS E POTENCIALIDADES DAS PEQUENAS CIDADES PARA O DESENVOLVIMENTO NO CONTEXTO DE UMA SOCIEDADE URBANA: ALGUNS APONTAMENTOS COM BASE NA REALIDADE DE FRUTAL-MG E SÃO GOTARDO-MG

população brasileira, ela apresenta crescimento maior que a população rural. De acordo com o autor, entre 1960 e 1980, a população agrícola passa de 15.454.526 para 21.163.729, ao passo que a população rural fica praticamente estacionária: 38.418 .798 em 1960, e 38.566.297 em 1980 (em 1970, são 41.054.054).

Tabela 2- São Gotardo -MG e Frutal-MG: População total residente, por localização urbana e rural (1970-2010).

\begin{tabular}{c|c|c|c|c|c|c|c}
\hline \multirow{2}{*}{ Ano } & \multirow{2}{*}{ Pop. } & \multicolumn{3}{|c|}{ São Gotardo } & \multicolumn{3}{c}{ Frutal } \\
\cline { 3 - 8 } & & Urb. & Rur. & Total & Urb. & Rur. & Total \\
\hline \multirow{2}{*}{$\mathbf{1 9 7 0}$} & Abs. & 8.624 & 95.99 & 18.223 & 17.735 & 12.934 & 30.669 \\
& $\%$ & 47,3 & 52,7 & 100 & 57,8 & 42,2 & 100 \\
\multirow{2}{*}{1980} & Abs. & 12.512 & 4.813 & 17.325 & 23.981 & 10.290 & 34.271 \\
& $\%$ & 72,2 & 27,8 & 100 & 70,0 & 30,0 & 100 \\
& Abs. & 16.520 & 3.177 & 19.697 & 33.232 & 8.192 & 41.424 \\
$\mathbf{1} 1991$ & $\%$ & 83,9 & 16,1 & 100 & 80,2 & 19,8 & 100 \\
& Abs. & 25.523 & 2.108 & 27.631 & 39.012 & 7.554 & 46.566 \\
& $\%$ & 92,4 & 7,6 & 100 & 83,9 & 16,2 & 100 \\
\multirow{2}{*}{2010} & Abs. & 30.061 & 1.758 & 31.819 & 46.089 & 7.379 & 53.468 \\
& $\%$ & 94,5 & 5,5 & 100 & 86,2 & 13,8 & 100 \\
\hline
\end{tabular}

Fonte: IBGE. Censos Demográficos. 1970, 1980, 1991 e 2000.

No contexto das pequenas cidades consideradas, verifica-se tais transformações relacionadas ao êxodo rural e ao padrão de ocupações. Em relação ao local de residência, para o contexto de São Gotardo as mudanças são relativamente mais intensas, pois o percentual da população urbana do município passou de 47,3 em 1970 para 94,4 em 2010, enquanto que em Frutal passou de 57,8 em 1970 para 86,2 em 2010 (Tabela 2). Conjectura essa, que pode estar atrelada às especificidades da modernização agrícola, que no caso de São Gotardo resultou em maior grau de importância deste setor em relação aos demais, Gráfico 3, e pela existência de outras atividades como o turismo, relativamente mais forte na área rural do município de Frutal, conforme explica Silva (2012). 
DESAFIOS E POTENCIALIDADES DAS PEQUENAS CIDADES PARA O DESENVOLVIMENTO NO CONTEXTO DE UMA SOCIEDADE URBANA: ALGUNS APONTAMENTOS COM BASE NA REALIDADE DE FRUTAL-MG E SÃO GOTARDO-MG

Gráfico 3: Percentual do pessoal ocupado com 18 anos ou mais por setores no Brasil, Minas Gerais e nos municípios mineiros de Frutal e São Gotardo (20002010).

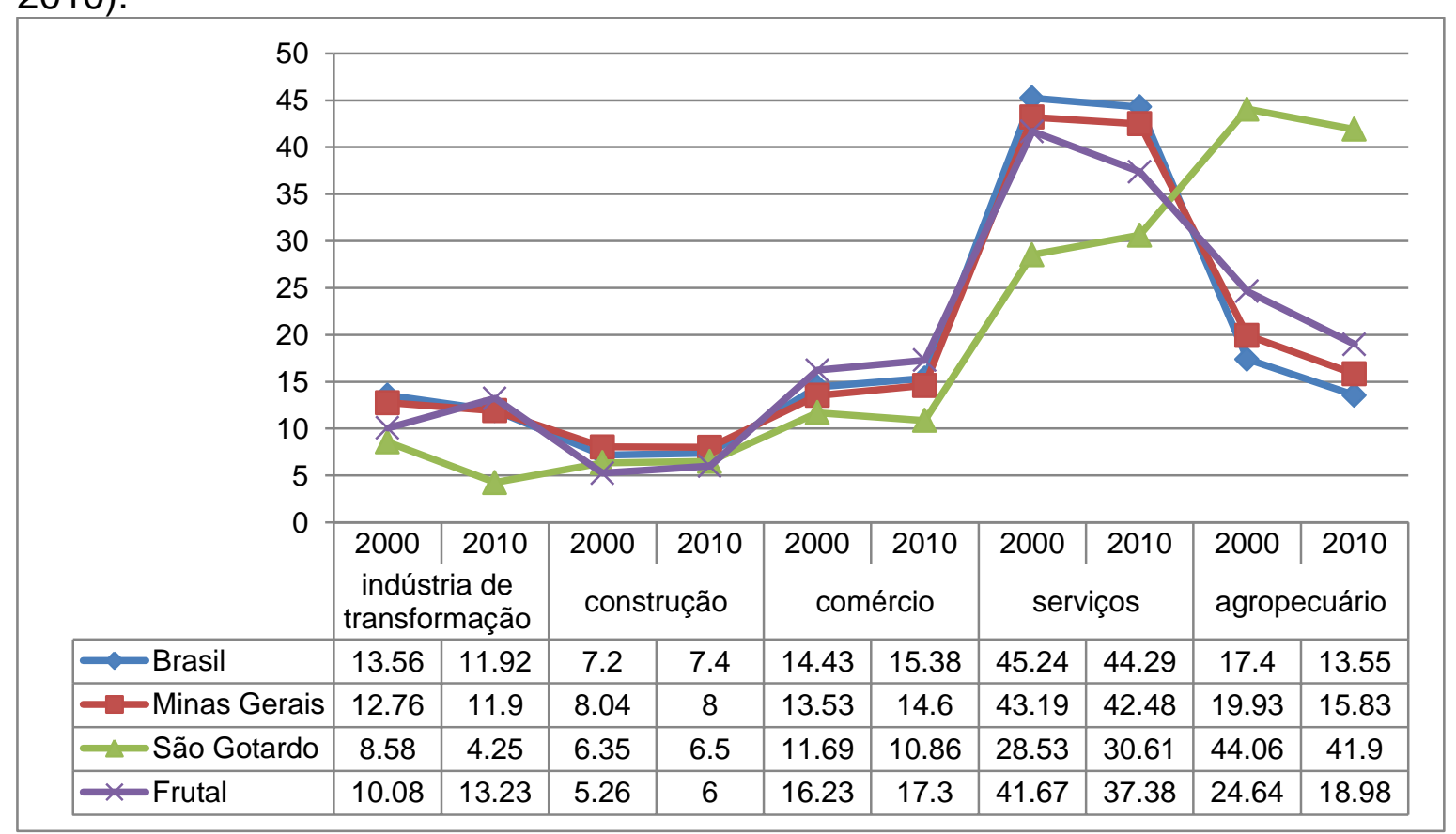

Fonte: PNUD (2013).

A existência da população agrícola nos municípios, no ano de 2010, é verificada pela comparação da quantidade de pessoas formalmente ocupadas no setor primário, segundo informações do Ministério do Trabalho e Emprego (MTE), 1.841 e 1.580 pessoas, em São Gotardo e Frutal respectivamente, com a quantidade de pessoas residentes na zona rural, segundo o censo demográfico do IBGE, 1.758 em São Gotardo e 5.999 pessoas em Frutal. Verifica-se que em São Gotardo a população agrícola é 83 pessoas, enquanto que em Frutal esta não é aparente por essa via. Ao comparar a população economicamente ativa com a população ocupada por local de residência, considerando os dados do censo IBGE de 2010, das pessoas com 10 anos ou mais ocupadas na semana de referência, verifica-se que, em São Gotardo, enquanto a PEA rural era de 1.218 pessoas a quantidade de pessoas ocupada R. Ra'e Ga - Curitiba, v. 35, p.7 -37 , Dez/2015 
DESAFIOS E POTENCIALIDADES DAS PEQUENAS CIDADES PARA O DESENVOLVIMENTO NO CONTEXTO DE UMA SOCIEDADE URBANA: ALGUNS APONTAMENTOS COM BASE NA REALIDADE DE FRUTAL-MG E SÃO GOTARDO-MG

no campo era de 6.818 , portanto com uma diferença de 5.600 pessoas. Já em Frutal a PEA rural era de 5.707 e as pessoas ocupadas no campo eram 4.885. Estes valores indicam a existência de um contingente populacional significativo da chamada população agrícola, nomeadamente no município de São Gotardo.

É comum em ambas as realidades a entrada de migrantes, sobretudo em função da oferta de trabalho, no campo (nomeadamente no caso de São Gotardo) e/ou nos serviços voltados para atender às demandas do campo (mais representativos em Frutal), vindos da região nordeste.

Tabela 3: São Gotardo-MG e Frutal- MG: População residente, por sexo e lugar de nascimento (1991, 2000 e 2010).

\begin{tabular}{|c|c|c|c|c|c|c|c|c|c|c|c|c|}
\hline \multirow{3}{*}{$\begin{array}{l}\text { Lugar de } \\
\text { origem }\end{array}$} & \multicolumn{6}{|c|}{ São Gotardo } & \multicolumn{6}{|c|}{ Frutal } \\
\hline & \multicolumn{2}{|c|}{ Total } & \multicolumn{2}{|c|}{ Homens } & \multicolumn{2}{|c|}{ Mulheres } & \multicolumn{2}{|r|}{ Total } & \multicolumn{2}{|c|}{ Homens } & \multicolumn{2}{|c|}{ Mulheres } \\
\hline & 2000 & 2010 & 2000 & 2010 & 2000 & 010 & 2000 & 2010 & 2000 & 010 & 2000 & 2010 \\
\hline Total & 27.631 & $\begin{array}{c}31.8 \\
19\end{array}$ & 14.173 & 16.096 & $6 \quad 13.458$ & 15.723 & 46.566 & $56 \quad 53.468$ & $8 \quad 23.255$ & 27.073 & $\begin{array}{ll}3 & 23 . \\
311\end{array}$ & 26.395 \\
\hline $\begin{array}{l}\text { Região } \\
\text { Norte }\end{array}$ & 35 & 82 & 17 & 20 & 19 & 63 & 145 & 345 & 58 & 173 & 87 & 172 \\
\hline $\begin{array}{l}\text { Região } \\
\text { Nordeste }\end{array}$ & 970 & $\begin{array}{c}3.33 \\
8\end{array}$ & 600 & 2.053 & 371 & 1.285 & 1.735 & 3.682 & 969 & 2.235 & 767 & 1.446 \\
\hline $\begin{array}{l}\text { Região } \\
\text { Sudeste }\end{array}$ & 25.882 & $\begin{array}{c}27.2 \\
80\end{array}$ & 13.180 & 13.450 & 12.702 & 13.830 & 43.212 & 47.933 & 21.629 & 23.875 & $\begin{array}{ll}5 & 21 . \\
583\end{array}$ & 24.058 \\
\hline Região Sul & 369 & 540 & 214 & 268 & 156 & 271 & 292 & 290 & 143 & 170 & 148 & 120 \\
\hline $\begin{array}{c}\text { Região } \\
\text { Centro- } \\
\text { Oeste }\end{array}$ & 336 & 444 & 145 & 179 & 191 & 265 & 1.142 & 910 & 445 & 510 & 697 & 400 \\
\hline $\begin{array}{l}\text { Brasil sem } \\
\text { especificar }\end{array}$ & - & 57 & - & 57 & - & - & 11 & 213 & - & 79 & 11 & 134 \\
\hline $\begin{array}{l}\text { País } \\
\text { estrangeiro }\end{array}$ & 38 & 78 & 18 & 68 & 20 & 10 & 28 & 96 & 11 & 31 & 17 & 65 \\
\hline
\end{tabular}

Fonte: IBGE - Censos Demográficos (2000 e 2010).

Conforme os dados do IBGE, tabela 3, após a região sudeste, onde se inserem os municípios, os residentes emigrantes vêm do nordeste, sobretudo dos estados do Maranhão, Ceará, Alagoas e Bahia, no caso de São Gotardo e da Bahia e Pernambuco no caso de Frutal. Dentre as demais regiões destacam-se os migrantes do Paraná na região sul, Goiás na região centro, Tocantins na região norte e São Paulo na região Sudeste, estes últimos, sobretudo no caso de Frutal, devido sua localização na divisa com este Estado. 
DESAFIOS E POTENCIALIDADES DAS PEQUENAS CIDADES PARA O DESENVOLVIMENTO NO CONTEXTO DE UMA SOCIEDADE URBANA: ALGUNS APONTAMENTOS COM BASE NA REALIDADE DE FRUTAL-MG E SÃO GOTARDO-MG

Em ambos os municípios predominam os migrantes vindos da região nordeste e do sexo masculino, posto que, o motivo principal dos deslocamentos é a busca por empregos no campo, que podem assegurar rendimentos relativamente bons, considerando o custo de vida nestas cidades. Conforme representado na tabela 4 , a maior parte dos ocupados possui rendimentos entre 3 e 5 salários mínimos, em ambas as cidades. Contudo, quando o foco são as empresas locais, conforme pesquisa do IBGE (2012), Diretoria de Pesquisas, Cadastro Central de Empresas, os salários médios mensais mínimos nos municípios são de 2,0 e 2,2 em São Gotardo e Frutal, abaixo das médias mineira e brasileira que são de 2,7 e 3,0, respectivamente. Além disso, nestas cidades observa-se que há uma tendência de evolução do rendimento médio, verifica-se que o percentual das pessoas com renda de até 1 salário mínimo teve redução significativa entre 2000 e 2010.

Tabela 4: \% pessoal ocupado de 18 anos ou mais por faixa de rendimento (2000 e 2010).

\begin{tabular}{ccccccccc}
\hline \multirow{2}{*}{ Lugar } & \multicolumn{2}{c}{ até 1 s.m } & \multicolumn{2}{c}{ até 2 s.m } & \multicolumn{2}{c}{ até 3 s.m. } & \multicolumn{2}{c}{ até 5 s.m. } \\
\cline { 2 - 9 } & $\mathbf{2 0 0 0}$ & $\mathbf{2 0 1 0}$ & $\mathbf{2 0 0 0}$ & $\mathbf{2 0 1 0}$ & $\mathbf{2 0 0 0}$ & $\mathbf{2 0 1 0}$ & $\mathbf{2 0 0 0}$ & $\mathbf{2 0 1 0}$ \\
\hline Brasil & 43,92 & 21,91 & 72,48 & 69,56 & 80,68 & 81,67 & 90,33 & 90,4 \\
Minas Gerais & 49,19 & 19,19 & 77,14 & 72,76 & 84,16 & 84,45 & 92,17 & 92,28 \\
São Gotardo & 35,76 & 14,15 & 77,15 & 72,00 & 85,71 & 85,49 & 93,16 & 93,61 \\
Frutal & 41,66 & 12,48 & 76,73 & 65,39 & 83,71 & 81,92 & 91,14 & 92,58 \\
\hline
\end{tabular}

Fonte: PNUD (2013).

É importante considerar que altos índices migratórios, especialmente de pessoas com baixo nível de qualificação, podem gerar maiores demandas em diferentes setores do município, sendo que, por vezes tais demandas, especialmente se não atendidas, podem implicar em problemas sociais. Neste caso, sobretudo o provimento dos serviços públicos, de infraestruturas básicas e da possiblidade de acesso à habitação estão entre as demandas mais importantes. Informações sobre as condições habitacionais mínimas fornecem uma aproximação da realidade das habitações do local, as quais, em ambos os municípios, conforme o gráfico 4, apresentam-se melhores do que o estado de Minas Gerais e o Brasil. 
Gráfico 4:Percentual das habitações com: água encanada, banheiro e água encanada, coleta de lixo e energia elétrica no Brasil, Minas Gerais e nos municípios mineiros de Frutal e São Gotardo (1991, 2000 e 2010).

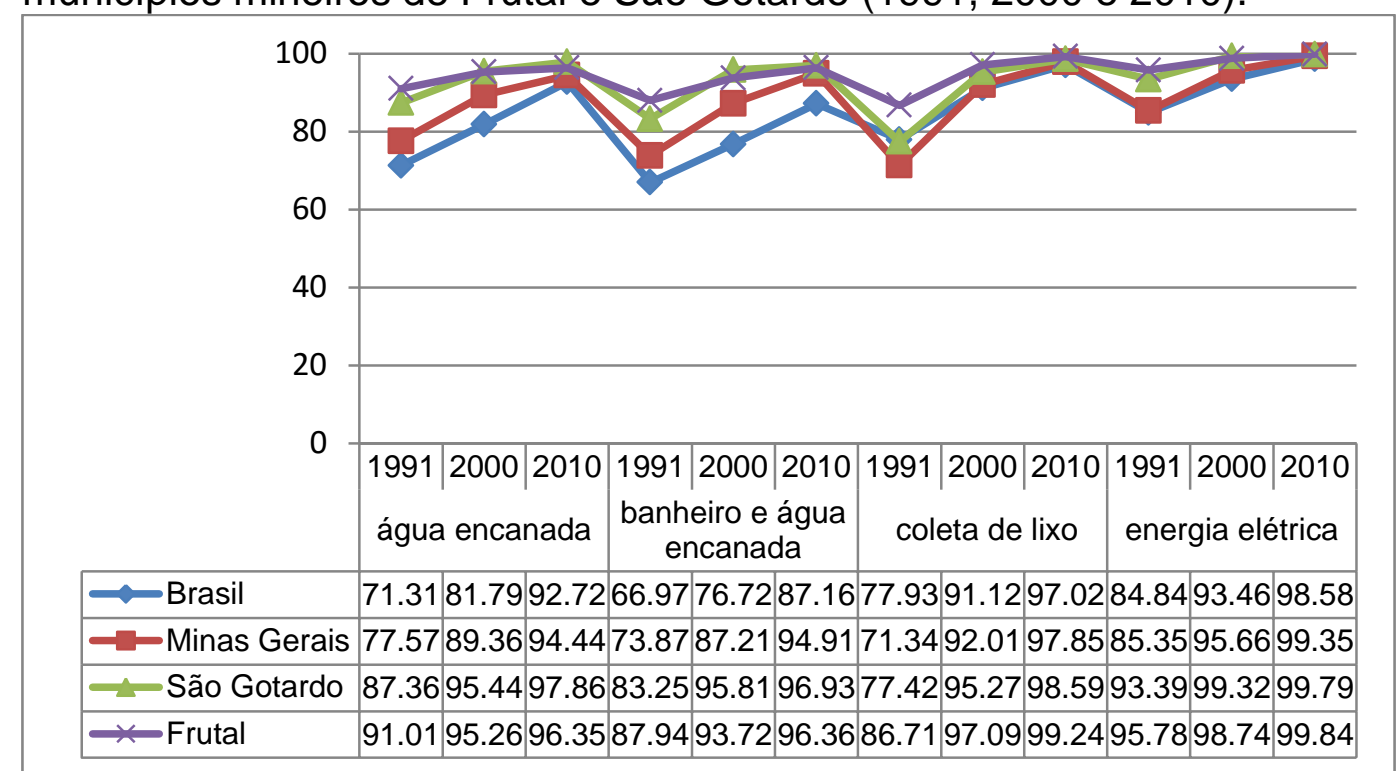

Fonte: PNUD (2013).

As condições habitacionais, como a presença de água encanada, presença de banheiro e coleta de lixo, podem ser proxys para compreender as condições de saúde da população, que, aparentemente não apresenta grandes problemas. Outra possibilidade é considerar as variáveis e os subíndices utilizados no painel de controle do ministério da saúde, o Índice de Desempenho do Sistema Único de Saúde (IDSUS), cujas notas variam de 0 a 10. Cabe destacar que o IDSUS se compõe de 24 indicadores associados aos temas de cobertura (acesso potencial ou obtido) com 14 indicadores, e efetividade (resultados esperados) do SUS, com 10 indicadores. Os indicadores de cobertura foram definidos em três áreas assistenciais (atenção básica, atenção ambulatorial e hospitalar de média complexidade e atenção ambulatorial e hospitalar de alta complexidade) enquanto que os indicadores de efetividade tomaram em consideração a atenção básica e a atenção ambulatorial e hospitalar de média e alta complexidade em conjunto. 
DESAFIOS E POTENCIALIDADES DAS PEQUENAS CIDADES PARA O DESENVOLVIMENTO NO CONTEXTO DE UMA SOCIEDADE URBANA: ALGUNS APONTAMENTOS COM BASE NA REALIDADE DE FRUTAL-MG E SÃO GOTARDO-MG

Para estes, os munícipios em questão, possuem índice de condições de saúde que encontram-se no enquadramento de a 4 a 6,0 em Frutal de 0,64 a 8,0 em São Gotardo, portanto bons. Na tabela 5, são apresentadas também outras avaliações relacionadas ao atendimento e as condições de saúde, as quais são de intermediários a bons, com exceção do acesso ambulatorial e hospitalar de alta complexidade, e da estrutura disponível do SUS que, apresentam índices baixos nestes municípios, o que está relacionado com a posição na rede urbana e a dimensão demográfica destes municípios e, grosso modo, não tem reflexos diretos na condição de saúde da população, posto que pela demanda de recursos infraestruturais e técnicos, os atendimentos de média e alta complexidade são realizados nos municípios que os possuem e se inserem na mesma região, a partir da "regionalização" de assistência à saúde ou mesmo de consórcios intermunicipais de saúde, logo em ambas as realidades são índices bons.

Tabela 5: Avaliação e índices das condições infraestruturais e da Saúde em Frutal-MG e São Gotardo-MG de acordo com IDSUS 2008-2012.

\begin{tabular}{|c|c|c|c|}
\hline \multirow{2}{*}{\multicolumn{2}{|c|}{ Variável }} & \multicolumn{2}{|c|}{ Valor } \\
\hline & & Frutal & São Gotardo \\
\hline \multirow{7}{*}{ Avaliação } & do acesso a atenção básica & maior que 7,9 & 7,0 a 7,9 \\
\hline & da efetividade da atenção básica & 7,0 a 7,9 & 7,0 a 7,9 \\
\hline & da atenção básica & maior que 7,9 & 7,0 a 7,9 \\
\hline & $\begin{array}{l}\text { do acesso ambulatorial de } \\
\text { hospitalar média complexidade }\end{array}$ & 4 a 4,9 & 5 a 5,9 \\
\hline & $\begin{array}{l}\text { do acesso ambulatorial } \\
\text { hospitalar de alta complexidade }\end{array}$ & 0 a 3,9 & 0 a 3,9 \\
\hline & $\begin{array}{l}\text { da efetividade ambulatorial e } \\
\text { hospitalar média e alta } \\
\text { complexidade }\end{array}$ & 5 a 5,9 & 0 a 3,9 \\
\hline & da média e alta complexidade & 4 a 4,9 & 0 a 3,9 \\
\hline \multirow[t]{2}{*}{ Índice } & $\begin{array}{c}\text { da condição de saúde da } \\
\text { população }\end{array}$ & 4,7 a 6,0 & 0,64 a 8 \\
\hline & de estrutura disponível do SUS & 0 a 0,14 & 0 a 0,14 \\
\hline
\end{tabular}

Fonte: IDSUS (2013).

No entanto, merece atenção especial, por estudos que possam analisar mais profundamente, com vistas a averiguar pressupostos para a realidade local, as relações entre o intenso uso de defensivos químicos, como 
ALVES, L. A.; SILVA, A. R. P

DESAFIOS E POTENCIALIDADES DAS PEQUENAS CIDADES PARA O DESENVOLVIMENTO NO CONTEXTO DE UMA SOCIEDADE URBANA: ALGUNS APONTAMENTOS COM BASE NA REALIDADE DE FRUTAL-MG E SÃO GOTARDO-MG

agrotóxicos e as causas de mortes, que nomeadamente no município de São Gotardo, onde o setor agropecuário moderno é predominante, se destacam as mortes por tumores, que representou $13 \%$ das mortes ocorridas em 2012, sendo para além das causas externas, a segunda causa de morte neste município. Em comparação com Frutal, cujo percentual de mortes por tumores é de $6,5 \%$. Além disso, cabe destacar que considerando o percentual das causas de mortes em relação à população municipal total ${ }^{6}$, igualmente os percentuais referentes ao município de São Gotardo são superiores aos de Frutal. É reconhecido por instituições como o Instituto Nacional do Câncer (INCA), que o uso de agrotóxico é prejudicial à saúde, onde os mais prejudicados são os trabalhadores agrícolas, porém toda a população está exposta pelo consumo da água, pelo ar e pelo consumo dos alimentos contaminados.

Nesse sentido, considerar a espacialização dos locais em que o uso de agrotóxicos é intenso em relação a distancia da localização de elementos como as aglomerações urbanas, os mananciais utilizados para abastecimento humano, etc. considerando também, para além da distância, elementos naturais como a direção predominante dos ventos, o relevo, as características dos solos, entre outros fatores, pode ser um primeiro encaminhamento para explicar as diferenças entre os casos de mortes por tumores em munícipios, cuja atividade da agricultura modernizada é predominante. Igualmente, os tipos de culturas e, por conseguinte de agrotóxicos que as mesmas requerem devem ser levados em consideração, pois algumas culturas necessitam de maior quantidade, bem como de tipos específicos de defensivos, que podem ter efeitos mais intensos e diretos na saúde da população.

Enfim, reafirma-se a necessidade de estudos científicos específicos sob diferentes enfoques e metodologias, para se chegar a conclusões mais precisas e, dependo dos resultados, sirvam de fundamentação para a tomada

\footnotetext{
${ }^{6}$ Para os anos de 2006, 2010 e 2012, em São Gotardo, a população total era de 33.495, 31.819 e 32.452 habitantes, respectivamente, já em Frutal a população total era de 50.367, 53.468 e 54.511 habitantes, respectivamente. Cabe destacar que para 2010 os dados são do censo demográfico enquanto para 2006 e 2012 são de estimativas populacionais publicadas pelo IBGE.
}

R. Ra'e Ga - Curitiba, v. 35, p.7 -37 , Dez/2015 
ALVES, L. A.; SILVA, A. R. P

DESAFIOS E POTENCIALIDADES DAS PEQUENAS CIDADES PARA O DESENVOLVIMENTO NO CONTEXTO DE UMA SOCIEDADE URBANA: ALGUNS APONTAMENTOS COM BASE NA REALIDADE DE FRUTAL-MG E SÃO GOTARDO-MG

de medidas, com vistas à resolução, ou pelo menos, mitigação de tais efeitos negativos das atividades da agricultura modernizada sobre a saúde da população local. 
ALVES, L. A.; SILVA, A. R. P

DESAFIOS E POTENCIALIDADES DAS PEQUENAS CIDADES PARA O DESENVOLVIMENTO NO CONTEXTO DE UMA SOCIEDADE URBANA: ALGUNS APONTAMENTOS COM BASE NA REALIDADE DE FRUTAL-MG E SÃO GOTARDO-MG

Quadro 1: Causas de morte nos municípios de Frutal e São Gotardo (2006, 2010, 2012).

\begin{tabular}{|c|c|c|c|c|c|c|c|c|c|c|c|c|}
\hline \multirow{3}{*}{ Causas de morte } & \multicolumn{6}{|c|}{ Frutal } & \multicolumn{6}{|c|}{ São Gotardo } \\
\hline & 2006 & 2010 & 2012 & 2006 & 2010 & 2012 & 2006 & 2010 & 2012 & 2006 & 2010 & 2012 \\
\hline & \multicolumn{3}{|c|}{ № absolutos } & \multicolumn{3}{|c|}{$\begin{array}{c}\text { \% em relação ao total } \\
\text { populacional }\end{array}$} & \multicolumn{3}{|c|}{ № absolutos } & \multicolumn{3}{|c|}{$\begin{array}{c}\text { \% em relação ao total } \\
\text { populacional }\end{array}$} \\
\hline Algumas doenças infecciosas e parasitárias & 20 & 12 & 10 & 0,040 & 0,022 & 0,018 & 5 & 6 & 5 & 0,015 & 0,0189 & 0,0154 \\
\hline Neoplasias (tumores) & 13 & 23 & 22 & 0,026 & 0,043 & 0,040 & 11 & 8 & 21 & 0,033 & 0,0251 & 0,0647 \\
\hline $\begin{array}{l}\text { Doenças sangue órgãos hemat e transt } \\
\text { imunitár }\end{array}$ & 0 & 3 & 3 & 0,000 & 0,006 & 0,006 & 2 & 1 & 0 & 0,006 & 0,0031 & 0,0000 \\
\hline $\begin{array}{l}\text { Doenças endócrinas nutricionais e } \\
\text { metabólicas }\end{array}$ & 11 & 15 & 19 & 0,022 & 0,028 & 0,035 & 5 & 8 & 14 & 0,015 & 0,0251 & 0,0431 \\
\hline Transtornos mentais e comportamentais & 3 & 0 & 2 & 0,006 & 0,000 & 0,004 & 3 & 1 & 3 & 0,009 & 0,0031 & 0,0092 \\
\hline Doenças do sistema nervoso & 4 & 1 & 7 & 0,008 & 0,002 & 0,013 & 1 & 1 & 5 & 0,003 & 0,0031 & 0,0154 \\
\hline Doenças do aparelho circulatório & 88 & 63 & 70 & 0,175 & 0,118 & 0,128 & 35 & 44 & 35 & 0,104 & 0,1383 & 0,1079 \\
\hline Doenças do aparelho respiratório & 61 & 47 & 46 & 0,121 & 0,088 & 0,084 & 14 & 17 & 20 & 0,042 & 0,0534 & 0,0616 \\
\hline Doenças do aparelho digestivo & 16 & 12 & 7 & 0,032 & 0,022 & 0,013 & 1 & 0 & 7 & 0,003 & 0,0000 & 0,0216 \\
\hline Doenças da pele e do tecido subcutâneo & 1 & 0 & 1 & 0,002 & 0,000 & 0,002 & 0 & 0 & 0 & 0,000 & 0,0000 & 0,0000 \\
\hline $\begin{array}{l}\text { Doenças sist.. osteomuscular e tec. } \\
\text { conjuntivo }\end{array}$ & 0 & 0 & 1 & 0,000 & 0,000 & 0,002 & 0 & 0 & 2 & 0,000 & 0,0000 & 0,0062 \\
\hline Doenças do aparelho geniturinário & 2 & 6 & 11 & 0,004 & 0,011 & 0,020 & 1 & 1 & 3 & 0,003 & 0,0031 & 0,0092 \\
\hline Algumas afec originadas no período perinatal & 10 & 3 & 3 & 0,020 & 0,006 & 0,006 & 3 & 0 & 0 & 0,009 & 0,0000 & 0,0000 \\
\hline $\begin{array}{l}\text { Malf cong deformid e anomalias } \\
\text { cromossômicas }\end{array}$ & 1 & 1 & 1 & 0,002 & 0,002 & 0,002 & 0 & 0 & 2 & 0,000 & 0,0000 & 0,0062 \\
\hline Sint sinais e achad anorm ex clín e laborat & 51 & 58 & 86 & 0,101 & 0,108 & 0,158 & 10 & 12 & 21 & 0,030 & 0,0377 & 0,0647 \\
\hline $\begin{array}{l}\text { Causas externas de morbidade } \mathrm{e} \\
\text { mortalidade }\end{array}$ & 37 & 41 & 47 & 0,073 & 77 & 0 & 14 & 10 & 23 & 042 & 0,0314 & 0,0709 \\
\hline Total & 318 & 285 & 336 & 0,631 & 0,533 & 0,616 & 105 & 110 & 161 & 0,313 & 0,3457 & 0,4961 \\
\hline
\end{tabular}

Fonte: MS/SVS/DASIS - Sistema de Informações sobre Mortalidade - SIM (2014). 
Parte-se do pressuposto de que o desenvolvimento econômico, a qualidade do lugar, a saúde, a qualidade de vida e bem-estar encontram-se intrinsicamente relacionados, pois igualmente decorrem de aspectos complexos e, portanto, devem ser abordados a partir de uma perspectiva sistêmica. Neste contexto, o Estado, juntamente com toda a população, a partir da participação, tem papel de destaque, mormente no que tange ao planejamento local, em sentido amplo. Destaca-se a importância da adesão pela população à inciativas que possam contribuir para as melhorias socioespaciais, com o objetivo último de alcançar o bem-estar. Portanto, o futuro das cidades, em última análise, decorre da escolha, em uma encruzilhada, da direção a seguir.

\section{CONSIDERAÇÕES FINAIS}

No século XXI, caracterizado por uma sociedade urbana, são vários os desafios postos às cidades, especialmente àquelas em que a urbanização ocorreu de forma tardia, porém rápida e sem o adequado provimento de infraestruturas. $A$ superação dos obstáculos, em grande medida passa pelo processo de planejamento e gestão, entretanto, para que estes possam ter resultados eficazes e efetivos é requerido o engajamento e a participação, que por sua vez demanda, dentre outros aspectos do conhecimento. Todos devem ter conhecimento para a participação nos processos de planejamento e de gestão local, afinal este é basilar à liberdade, à democracia e à capacidade de inovação.

Além disso, para mitigar os efeitos da urbanização rápida, sobretudo com foco nas pequenas cidades, mas não somente, os vários processos relacionados às questões econômicas, sociais e infraestruturais (abastecimento de água, tratamento dos resíduos, etc) devem ser tratados de forma integrada, segundo a particularidade de cada cidade, ainda que exemplos bem-sucedidos possam ser considerados e adaptados às particularidades locais.

Para as cidades pequenas, que conforme destacado por Correa (2007, p.5), por vezes, sofrem os reflexos das transformações no mundo agrícola, o que paradoxalmente implica no crescimento econômico e no agravamento das condições para o bem-estar, pelo êxodo rural, ou como colocado pelo uso intensivo de 
defensivos, os quais podem ter reflexos nas condições de saúde da população. $O$ provimento de infraestruturas, a gestão eficiente dos recursos, e outras ações que coadunem com os princípios da sustentabilidade, estão entre os principais condicionantes para o bem-estar futuro, no sentido de assegurar de modo harmonioso o crescimento econômico com boas condições ambientais e sociais. Porém, se de um lado a dimensão espacial seja favorável para que as ações possam ter uma ampla abrangência, de outro lado os recursos técnicos e humanos, muitas vezes, são limitadores.

Assim, por se tratar de processos recentes, portanto ainda balizando a transição para uma nova realidade, a intensa urbanização e o papel das pequenas cidades nesta conjectura, seus desafios para o alcance da qualidade ambiental e o bem-estar, consistem em temas intrigantes, complexos e que precisam ser considerados por estudiosos de diferentes áreas. Os breves apontamentos aqui realizados visam destacar a relevância e despertar o interesse para tais questões.

\section{REFERÊNCIAS}

ALENTEJANO, P. R. As relações campo-cidade no Brasil do século XXI. Terra Livre, São Paulo, v. 2, n. 21, p. 25-39. 2003.

BACELAR, W. K. de A. A pequena cidade nas teias da aldeia global : relações e especificidades sócio - políticas nos municípios de Estrela do Sul, Cascalho Rico e Grupiara - MG, 411f. 2008. Tese (Doutorado em Geografia). Instituto de Geografia da Universidade Federal de Uberlândia, UFU. Uberlândia.

BAENINGER, R. Deslocamentos populacionais, urbanização e regionalização. Revista Brasileira de Estudos Populacionais, Brasília, v. 15, n.2, p. 67- 81, 1998.

CASTELLS, M. A sociedade em rede: A era da informação: economia, sociedade e cultura. São Paulo: Paz e Terra. 1999.

CARLOS, A. F. A. Seria o Brasil "menos urbano do que se calcula?". Disponível em: <http://www.geografia.fflch.usp.br/publicacoes/geousp/geo>. Acesso em: mar. 2014.

CORRÊA, R. L. O estudo da rede urbana: uma proposição metodológica. Revista Brasileira de Geografia. Rio de Janeiro: IBGE, n. 50 n.2, p. 107-127, abr./jun.1988. 
. Rede urbana e formação espacial - uma reflexão considerando o Brasil. Revista Território, Rio de Janeiro, ano v, n. 8, p. 121-129, 2000.

Rede urbana: reflexões, hipóteses e questionamentos sobre um tema negligenciado. Cidades, Presidente Prudente, v. 1, n. 1, p. 65-78, 2004.

.Perspectivas da urbanização brasileira - uma visão geográfica para o futuro próximo. In: SIMPÓSIO NACIONAL DE GEOGRAFIA URBANA (SIMPURB), X, 2007, Florianópolis: 2007.

DOWBOR, L. Série Atlas Brasil 2013 - Desenvolvimento Humano em debate. 2013. Entrevista concedida ao PNUD Brasil. 2014. Disponível em: <http://www.youtube.com/user/PNUDBrasil >. Acesso em: 30 mar. 2014.

ELIAS, D. Novas dinâmicas territoriais no Brasil agrícola. In: SPOSITO, Eliseu Saverio; SPOSITO, Maria Encarnação Beltrão; SOBARZO, Oscar. (Orgs.). Cidades médias: produção do espaço urbano e regional. São Paulo: Expressão Popular, 2006, p. $279-303$.

Agronegócio e novas regionalizações no Brasil. Revista Brasileira de Estudos Urbanos e Regionais, Rio de Janeiro, v.13, n.2, p. 153-167, 2011.

FERREIRA, J. S. W. Globalização e urbanização subdesenvolvida. São Paulo Perspec. v.14 n.4, p. 10-20. 2000.

GUERREIRO, E. P. Cidade digital: infoinclusão social e tecnologia em rede. São Paulo: Editora Senac. 2006.

IBGE. (vários anos). Censo demográfico de 1970, 1980, 1991, 2000, 2010. Disponível em: <http://biblioteca.ibge.gov.br/>. Acesso em: 30 mai. 2014.

Arranjos Populacionais e Concentrações Urbanas do Brasil. 2015. Disponível em:<ftp://geoftp.ibge.gov.br/organizacao_territorial/arranjos populacionais/arranjos_populacionais.pdf>. Acesso em: 30 mai. 2015.

IDSUS. Índice de desempenho do sistema único de saúde. Ministério da saúde. Disponível em: <www.saude.gov.br/idsus>. Acesso em: 30 mai. 2014

JURADO DA SILVA, P. F. Cidades pequenas e indústria: contribuição para a análise da dinâmica econômica na região de Presidente Prudente-SP. 2011. Dissertação (Mestrado em Geografia). Departamento de Geografia da Faculdade de Filosofia, Ciências e Letras, Unesp. Presidente Prudente.

MARICATO, E. Urbanismo na periferia do mundo globalizado: metrópoles brasileiras. São Paulo em Perspectiva, São Paulo, v. 14. n. 4. p.21-33. 2000. 
MELO, N. A. de; SOARES, B. R. Pequenas cidades: reflexões sobre questões sócioambientais. Caminhos de Geografia Uberlândia, v. 12, n. 37 mar/2011 p. 124 $141,2010$.

MONBEIG P. O estudo geográfico das cidades. Cidades. v. 1, n. 2, p. 277-314, 2004.

OLIVEIRA, B. S.; SOARES, B. R. O papel das cidades locais no Triângulo Mineiro e Alto Paranaíba (MG) no contexto regional. Revista Horizonte Científico, PROPP/UFU, Uberlândia, n.2, p. 1-25, 2003. <Disponível em: http://www.geografiaememoria.ig.ufu.br/downloads/Beatriz_Ribeiro_Soares_O_PAP EL_DAS_CIDADES_LOCAIS_DO_TRIANGULO_MINEIRO\%20E.pdf >. Acesso em: 26 mai. 2014.

PNUD. Atlas do desenvolvimento humano no Brasil. Brasil. 2013. Disponível em: < http://www.atlasbrasil.org.br/2013/>. Acesso em: 30 mar. 2014.

SILVA, A. R. de P. As transformações socioespaciais de Frutal-MG. 2012. Dissertação (Mestrado em Geografia). Instituto de Geografia, Universidade de Federal de Uberlândia, Uberlândia.

RODRIGUES, A. M. A cidade como direito. Scripta Nova. Revista Electrónica de Geografía y Ciencias Sociales. Barcelona: Universidad de Barcelona, 1 de agosto de 2007, v. 9, n. 245 (33) s/p. Disponível em: <.http://www.ub.es/geocrit/sn/sn24533.htm>. Acesso em: 26 mai. 2014.

SANTOS, M. O espaço dividido: os dois circuitos da economia urbana dos países subdesenvolvidos. Rio de Janeiro: Francisco Alves. 1979.

. Manual de Geografia Urbana. 3. ed. São Paulo: Editora da Universidade de São Paulo. 2008.

Urbanização brasileira. São Paulo: Hucitec. 2009.

SOARES, W.; ALMEIDA, R. M. V.R.; MORO, S. Trabalho rural e fatores de risco associados ao regime de uso de agrotóxicos em Minas Gerais, Brasil. Cad. Saúde Pública, Rio de Janeiro, v.19, n.4 p.1117-1127, jul-ago, 2003.

SOUZA, M. L. de. ABC do Desenvolvimento Urbano. Rio de Janeiro: Bertrand Brasil. 2005. 
STEFFEN, G. P. K.; STEFFEN, R.B.; ANTONIOLLI, Z.I. Contaminação do solo e da água pelo uso de agrotóxicos. Tecno-lógica, Santa Cruz do Sul, v. 15, n. 1, p. 1521, jan./jun. 2011.

UN. United Nations. Disponível em: < http://www.un.org/en/>. Acesso em: 30 mar. 2014.

UN-HABITAT. United Nations Human Settlements Programme. State of the world's cities 2012/2013. Prosperity of Cities. Disponível em: < https://sustainabledevelopm ent.un.org/content/documents/745habitat.pdf> Acesso em: 30 mar. 2014. 